\title{
POR UMA ESCOLA PLURAL, INTEGRADA E COM PARTIDOS
}

\author{
Caroindes Julia Corrêa Gomes (UFSCar)* \\ https://orcid.org/0000-0003-0191-806X \\ Vânia Gomes Zuin (UFSCar)** \\ https://orcid.org/0000-0003-4452-4570
}

\section{RESUMO}

Este trabalho problematiza, à luz da Aufklärung, as possibilidades de uma práxis educacional apartidária ao almejarmos uma educação democrática em defesa da liberdade, autonomia e justiça social. A partir das ideias de Immanuel Kant, apresentamos um diálogo com diferentes perspectivas históricas e filosóficas da Aufklärung a fim de refletir a gênese do Movimento Escola sem Partido. Ao impedir uma abordagem plural, o Movimento impossibilita o acesso aos conteúdos e informações historicamente situados e necessários para apreendermos e transformarmos as realidades, promovendo (ainda mais) a invisibilidade e a inexistência das maiorias submissas. A igualdade de direitos não se concretizará baseada em um Projeto mistificador e alienante; mas ao contrário, somente na liberdade de ensinar, aprender, se realizar e se constituir como sujeitos esclarecidos e que ousem saber.

Palavras-chave: Escola sem Partido. Aufklärung. Igualdade.

\section{ABSTRACT}

\section{FOR A PLURAL, INTEGRATED SCHOOL AND WITH PARTIES}

This article discusses, on the perspective of Aufklärung, the possibilities of a non-partisan educational praxis aiming a democratic education in defense of the subjects' liberty and autonomy. Premised on Immanuel Kant's ideas, we present a dialogue with different historical and philosophical perspectives of Aufklärung in order to reflect on the genesis of the Movement School without Party. By preventing a plural approach, the Movement renders it impossible for the access to the content and information historically dated and needed to grasp and transform the realities, promoting (even more) the invisibility and the inexistence of the subservient majorities. The equality of rights will not be achieved based on a mystifying and alienating Project; but only on the freedom of teaching, learning, fulfilling and developing as enlightened subjects that dares to know.

Keywords: School without Party. Aufklärung. Equality.

\footnotetext{
Doutoranda do Programa de Pós-Graduação em Educação na Universidade Federal de São Carlos (UFSCar).

E-mail: caroindes@gmail.com

* Doutora em Educação e em Química pela Universidade de São Paulo (USP). Professora da Universidade Federal de São Carlos (UFSCar) junto ao Departamento de Química (Associada), credenciada ao Programa de Pós-Graduação em Química e ao Programa de Pós-Graduação em Educação. E-mail: vaniaz@ufscar.br
} 


\section{RESUMEN}

\section{POR UNA ESCUELA PLURAL, INTEGRADA Y CON PARTIDOS}

Este estudio problematiza, a la luz de la Aufklärung, las posibilidades de una praxis educativa no partidista al buscar una educación democrática en defensa de la libertad, la autonomía y la justicia social. Basado en las ideas de Immanuel Kant, presentamos un diálogo con diferentes perspectivas históricas y filosóficas de la Aufklärung con la intención de reflexionar el génesis del Movimiento Escuela sin Partido. Al evitar un bordaje plural, el Movimiento impide el acceso a los contenidos e informaciones históricamente establecidos y necesarios para comprender y transformar realidades, promoviendo (aún más) la invisibilidad y la inexistencia de mayorías sumisas. La igualdad de derechos no se concretará basada en un Proyecto mistificador y alienante; pero, por el contrario, solo en la libertad de enseñar, aprender, realizarse y constituirse como sujetos iluminados y que se atreven a conocer.

Palabras clave: Escuela sin Partido. Aufklärung. Igualdad.

\section{Introdução ${ }^{1}$}

Assim como em outras épocas, nosso contexto sócio-histórico também é definido por controvérsias e incertezas que demonstram a barbárie, o preconceito e a intolerância materializados nas relações e discursos hoje em pauta.

Ao mesmo tempo em que produz as condições para um mundo mais justo e igualitário, o aumento da produtividade técnico-científica e econômica realiza o seu inverso: a desigualdade e a opressão - consumadas na violência experienciada por aqueles e aquelas que possuem sua liberdade roubada. Liberdade que lhes é negada pela cor de sua pele, por sua orientação sexual ou religião, por ser mulher, ou tantas outras razões que se manifestam como impossibilidade e renúncia de ser e existir.

A Constituição Federal de 1988, em seu artigo $5^{\circ}$, garante a todos e todas, brasileiros, brasileiras e estrangeiros e estrangeiras residentes no país, o direito inviolável à igualdade, à liberdade, à vida e à segurança, atestando a

1 Ressaltamos que este texto é inédito, não tendo sido publicado parcial ou integralmente em nenhum outro meio de divulgação científica, e que também seguimos os procedimentos éticos durante a realização de sua pesquisa e escrita. As autoras agradecem os apoios recebidos do CNPq (166762/2018-0, 310149/2017-7, 421096/2016-0 e 311000/2014-2), FAPESP (18/11409-0 e 17/25015-1) e IUPAC (2013-041-3-300), do PPGE e DQ-UFSCar. equidade perante a lei e o respeito à diversidade de crenças, etnias, costumes e concepções (BRASIL, 1988).

Adorno e Horkheimer (2006, p. 13) afirmam que "a liberdade na sociedade é inseparável do pensamento esclarecedor", mas as configurações sócio-históricas concretizadas são a causa substancial para a regressão em todos os âmbitos sociais, pois "se o esclarecimento não acolhe dentro de si a reflexão sobre esse elemento regressivo, ele está selando seu próprio destino" (ADORNO; HORKHEIMER, 2006, p. 13).

A falsa liberdade e a igualdade do direito à injustiça impedem, muitas vezes, que os sujeitos problematizem e reconheçam a violência (em todas as suas formas) como viabilidade e realidade histórica que pode ser transformada (FREIRE, 2019). Na medida em que se mostra como situação coletiva concreta e intransponível, naturalizando construções sociais que não são (e não devem ser) naturais, a existência desigual se efetiva, reflete na particularidade e serve, ela própria, à sua autoconservação.

Isso oportuniza as convicções na função formativa da escola, compreendendo-a como o espaço de reproduções historicamente construídas, mas, principalmente, o lugar da 
resistência, da pluralidade, da constituição e realização dos sujeitos.

Em tempos sombrios e perversos - como os vivenciados - direcionaremos as discussões deste trabalho à importância de uma educação democrática que possibilite a liberdade, a autonomia e a justiça social. Para apresentarmos a gênese dessa educação esclarecedora, fundamentaremos nosso discurso em diferentes perspectivas históricas e filosóficas da Aufklärung ${ }^{2}$ que, de acordo com Adorno e Horkheimer (2006, p. 7), “designam o processo pelo qual uma pessoa vence as trevas da ignorância e do preconceito em questões de ordem prática (religiosas, políticas, sexuais etc.)".

Ainda sobre a Constituição Federal de 1988,

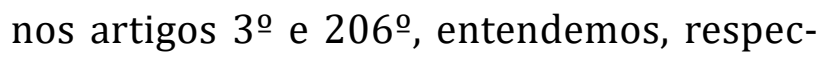
tivamente, como objetivos fundamentais da República Federativa do Brasil e do ensino, a construção da justiça, da liberdade e igualdade e uma formação fundamentada no respeito e direito às diversidades.

Art. 3ํㅡㄴ Constituem objetivos fundamentais da República Federativa do Brasil:

I - construir uma sociedade livre, justa e solidária;

II - garantir o desenvolvimento nacional;

III - erradicar a pobreza e a marginalização e reduzir as desigualdades sociais e regionais;

IV - promover o bem de todos, sem preconceitos de origem, raça, sexo, cor, idade e quaisquer outras formas de discriminação.

\section{[...]}

Art. 206. 0 ensino será ministrado com base nos seguintes princípios:

II - Liberdade de aprender, ensinar, pesquisar e divulgar o pensamento, a arte e o saber;

III - Pluralismo de ideias e de concepções pedagógicas, e coexistência de instituições públicas e privadas de ensino. (BRASIL, 1988).

2 Adorno e Horkheimer (2006) discorrem que a tradução da Aufklärung por esclarecimento, ao invés de utilizar os termos iluminismo ou ilustração - mais comumente usado para se referir à Época ou Filosofia das Luzes -, traduz as razões históricas e filosóficas que possibilitam aos sujeitos a autonomia, a individualidade e a criticidade.
Corroborando com a percepção da pluralidade e liberdade de ideias, pensamentos e concepções pedagógicas, compreendemos que a escola e as relações estabelecidas em seus espaços, incluindo os processos de ensino e aprendizagem, não são neutros em consequência de um dos objetivos principais da educação, a saber: a socialização, que propicia formas de agir e pensar na sociedade, cria e projeta representações historicamente situadas (SALLES, 2017).

Destarte, também é inevitável não concentrarmos as discussões seguintes à expectativa de uma Escola sem Partido, em evidência nos discursos nacionais há algum tempo e materializada nas práticas sociais - convenientemente silenciadas. Afinal, quais as possibilidades de uma práxis educacional apartidária em tempos sombrios e perversos?

Fundado pelo advogado Miguel Nagib em 2004, o Movimento Escola sem Partido (MESP) é definido como "uma iniciativa conjunta de estudantes e pais preocupados com o grau de contaminação político-ideológica das escolas brasileiras, em todos os níveis: do ensino básico ao superior" (ESCOLA SEM PARTIDO, 2020a).

A principal estratégia do Movimento foi a criminalização da relação entre professores, professoras e estudantes, pressionando-se assembleias estaduais e municipais a fim de que incorporassem seus ideais como sendo projetos de lei. Apesar de muitos desses projetos que tramitavam nas Câmaras Municipais, Assembleias Estaduais e no Congresso Nacional serem considerados inconstitucionais ${ }^{3}$ (NICOLAZZI, 2016), o MESP ainda prevalece como possibilidade e, em nossa percepção, também vem estimulando e fortalecendo práticas antidemocráticas.

Exemplo recente foi a medida liminar profe-

3 Podemos citar como exemplo o PL no 867/2015, protocolado pelo antigo Deputado Federal Izalci (PSDB/ DF), que pretendia alterar a Lei de Diretrizes e Bases da Educação Nacional (LDB) ao incluir um programa "Escola sem Partido", pressupondo a neutralidade política da educação e o desenvolvimento de práticas não conflituosas com as convicções religiosas e morais dos pais ou responsáveis (MIGUEL, 2016; NICOLAZZI, 2016). 
rida pelo atual Governador de São Paulo, João Doria, que recolheu apostilas de Ciências da $8^{a}$ série do ensino fundamental ao considerá-las impróprias. ${ }^{4}$ A Secretaria de Educação do Estado de São Paulo afirmou que a ação ocorreu "por entender que a abordagem 'ninguém nasce homem nem mulher' expressa na apostila é equivocada por não apresentar fundamentação científica" (JUÍZA..., 2019). Importante mencionarmos que a Instituição ainda complementou, como justificativa, que suas ações são pautadas no "respeito à diversidade" (JUÍZA..., 2019), embora o Governador tenha publicado em seu perfil particular no Twitter: "não concordamos e nem aceitamos apologia à ideologia de gênero" (JUÍZA..., 2019).

A fim de desenvolvermos uma compreensão de escola democrática, que oportunize aos sujeitos ser e existir sócio-historicamente e sem distinções, o objetivo deste texto é: refletir, à luz da Aufklärung, as possibilidades de uma práxis educacional apartidária quando almejamos uma educação em defesa da liberdade, autonomia e justiça social. Apresentaremos um diálogo partindo das ideias de Immanuel Kant (1724-1804) sobre a Aufklärung para, então, problematizarmos a gênese do Movimento Escola sem Partido.

\section{Liberdade, autonomia e a dialética da Aufklärung ${ }^{5}$}

No atual discurso da falsa liberdade e da igualdade do direito à injustiça, principiaremos a discussão da Aufklärung recorrendo, inicialmente, à filosofia de Kant e, em especial, ao seu artigo publicado no periódico Berlinische Monatsschrift em 1784, com o título "O que é o esclarecimento (Aufklärung)? (KANT, 1974).

Para Kant (1974), a formação dos sujeitos está associada aos ideais de autonomia, liberdade e maioridade. A questão "o que é o

4 A Justiça do Estado de São Paulo concedeu liminar anulando o ato do Governador (JUÍZA..., 2019).

50 título remete aos escritos de Adorno e Horkheimer (2006) - também presente nas discussões. esclarecimento?" pressupõe a autonomia dos homens e mulheres na medida em que se libertam das tutelas e são capazes de pensar por si próprios, pois "o esclarecimento é a saída do homem de sua menoridade, da qual ele próprio é culpado" (KANT, 1974, p. 100).

Em sua exposição sobre a concepção kantiana de saída da menoridade, Kahlmeyer-Mertens (2012) afirma que depender das diretivas de outrem representa, muitas vezes, uma postura cômoda e conveniente por se caracterizar como desincumbência de suas obrigações. Em função disso, a menoridade, ou incapacidade de se orientar por sua razão, recairia aos sujeitos como culpa e débito consigo mesmo.

A expressão latina sapere aude! - que pode ser traduzida ao português como ousar saber é apresentada por Kant (1974) como elemento inicial do processo da Aufklärung, pois se trata da coragem e da ousadia de ir além daquilo que é imposto. Ao sair da menoridade, o sujeito servir-se-ia de si mesmo e se apropriaria da razão - livre de qualquer juízo exterior -, possibilitando a autonomia. 0 juízo não seria determinado por nada além da razão que, por sua vez, se autodeterminaria.

De acordo com Foucault (2000), ao considerar a coragem e a ousadia como elemento inicial à Aufklärung, Kant também a teria compreendido como um ato coletivo, por meio do qual se propõe uma palavra de ordem - aos outros e a nós mesmos. Os sujeitos são agentes e elementos do processo da Aufklärung, já que "podem ser seus atores à medida que fazem parte dele; e ele se produz à medida que os homens decidem ser seus atores voluntários" (FOUCAULT, 2000, p. 338).

Foucault (2000) complementa que a saída da menoridade, tal como apresentada por Kant (1974), depende do uso da razão autodeterminada, que "não se relaciona com um uso qualquer da razão, mas com um uso da razão no qual esta não tem outra finalidade" (FOUCAULT, 2000, p. 339).

Kant (1974) compreende a razão como faculdade humana e relacionada à liberdade, 
sendo fundamental para que os homens e mulheres possam servir-se de si e fazer o uso público e privado da mesma. 0 autor ainda discorre que todos e todas são livres e que as suas liberdades podem ser operadas de maneira individual. No entanto, as ações humanas não são promovidas apenas segundo fins particulares; ao contrário, elas são desenvolvidas por leis naturais - histórica e socialmente construídas. Ser esclarecido não significa ir contra a autoridade instituída, tampouco a obediência cega e inquestionável. 0 uso público da razão representa agir em conformidade com as circunstâncias e refletir criticamente acerca delas (KAHLMEYER-MERTENS, 2012).

Adorno e Horkheimer (2006) consideram que a Aufklärung produziu uma razão que, para se constituir, converteu o próprio homem em mercadoria e objeto de dominação. "No sentido mais amplo do progresso do pensamento, o esclarecimento tem perseguido sempre o objetivo de livrar os homens do medo e de investi-los na posição de senhores. Mas a terra totalmente esclarecida resplandece sob o signo de uma calamidade triunfal" (ADORNO; HORKHEIMER, 2006, p. 17).

Chauí (1995) afirma que a razão instrumental - também denominada por Adorno e Horkheimer de razão iluminista - surge quando o sujeito se apropria do conhecimento para dominar e controlar a natureza e os próprios seres humanos. A ciência e a técnica submetem a natureza ao controle humano e, em consequência, são capazes de livrá-los do temor que o mundo natural representa. Contudo, "o mito converte-se em esclarecimento, e a natureza em mera objetividade. 0 preço que os homens pagam pelo aumento de seu poder é a alienação daquilo sobre o que exercem o poder" (ADORNO; HORKHEIMER, 2006, p. 21).

Adorno e Horkheimer (2006) discorrem que a ciência também se reduz a mito na medida em que nega aquilo que não é racional, pois, na pretensão de dominar todas as coisas por meio da técnica, há um projeto unificador que possibilita a categorização e a racionalização. “A lógica formal era a grande escola da unificação. Ela oferecia aos esclarecedores o esquema da calculabilidade do mundo" (ADORNO; HORKHEIMER, 2006, p. 20).

De acordo com esses autores, ao quantificar e igualar coisas distintas por meio da racionalização, a sociedade burguesa torna o heterogêneo comparável - um equivalente geral que é matematicamente formalizado e mantém o pensamento preso à imediaticidade, já que o conhecimento se restringe à sua repetição. Com o mundo totalmente matematizado, o homem acreditou estar a salvo do mito, mas "o esclarecimento regride à mitologia da qual jamais soube escapar" (ADORNO; HORKHEIMER, 2006, p. 29).

Adorno e Horkheimer (2006) afirmam que há o pressuposto da valorização individual na sociedade capitalista, mas as identidades e individualidades são destruídas com a homogeneização do coletivo. A igualdade - compreendida como liberdade - torna-se fetiche quando o próprio ser humano também pode ser mensurável pelo trabalho. A Aufklärung elimina o incomensurável, modela os homens e mulheres e lhes fornece a característica de mercadoria; a igualdade do direito à injustiça.

A racionalidade dominou o sujeito e o transformou em irracional; o postulado científico de libertá-lo dos mitos eliminou a submissão da natureza, mas o fez submisso à mensurabilidade, à repetição e à falsa unidade coletiva.

No momento em que uma sociedade vive uma época assim, o próprio irracionalismo mitificador passa a constituir um de seus temas fundamentais, que terá, como seu oposto combatente, a visão crítica e dinâmica da realidade que, empenhando-se em favor do seu desvelamento, desmascara sua mitificação e busca a plena realização da tarefa humana: a permanente transformação da realidade para a libertação dos homens. (FREIRE, 2019, p. 129-130).

Freire (2019) discorre que a libertação dos homens e mulheres - também interpretada como humanização - é uma práxis que implica a ação e a reflexão sobre o mundo para transformá-lo, sendo condição indispensável para 
que eles e elas se compreendam como sujeitos histórico-sociais inconclusos e conscientes de sua inconclusão, percebendo a realidade como projeto e possibilidade a ser transformada.

Ao encontro dessa perspectiva, entendemos (e também defendemos) a importância de apreender a totalidade em que nos inserimos para realizarmos uma análise crítica de suas inter-relações e desvelarmos as contradições e impossibilidades que nos são colocadas. Ainda que a modernidade não tenha proporcionado nos tornar maiores, refletir sobre a questão é uma maneira eficaz de realizar uma crítica constante de nós mesmos, uma "análise histórica dos limites que nos são colocados e prova de sua ultrapassagem possível" (FOUCAULT, 2000, p. 351). Para Foucault (2000), essa reflexão consiste em compreender as práticas concretas e materializadas no individual, nas diferenças; desconstruindo razões universais e totalitárias. 0 trabalho crítico implica, também, a fé na Luzes: "ele sempre implica, penso, o trabalho sobre nossos limites, ou seja, um trabalho paciente que dá forma à impaciência da liberdade" (FOUCAULT, 2000, p. 345).

À vista disso, gostaríamos de adentrar a problematização do Movimento Escola sem Partido, a fim de entendermos sua gênese e desmistificarmos as realidades camufladas, apreendendo a liberdade, a autonomia e a justiça social como projeto e possibilidade, como resultado de uma práxis que implica nossa ação e reflexão sobre o mundo para transformá-lo (FREIRE, 2019).

\section{A gênese do Movimento Escola sem Partido}

O Movimento Escola sem Partido foi ignorado até meados de 2010 - quando passou a ser mais frequente nos discursos educacionais brasileiros e encontrou apoio de vários setores da sociedade e também da classe política mais conservadora. Em 2014, Miguel Nagib converteu o discurso do Movimento em um anteprojeto de lei, divulgando-o em um site jun- tamente com demais informações pertinentes ao assunto, como, por exemplo, seus objetivos e referenciais, que incluem o livro "Professor não é educador", de Armindo Pereira (MIGUEL, 2016).

Importante mencionarmos que uma das teses centrais desse livro consiste na ideia de que o professor e a professora que educam estariam usurpando uma das funções sagradas da família. Armindo Pereira afirmou, em uma entrevista, que esse modelo permaneceu e ainda permanecerá durante muito tempo, pois ser educador e educadora é uma questão de simpatia: "para isso não é necessário curso algum, não precisa de diploma e todo professor torna-se educador, de qualquer disciplina" (WURMEISTER, 2012).

Após dois anos, em outubro de 2016, foram contabilizados 40 projetos de lei em Câmaras Municipais, Assembleias Estaduais e no Congresso Nacional inspirados, de alguma forma, pelo anteprojeto do MESP (SALLES, 2017).

Atualmente encontramos dois sites relacionados especificamente ao Escola sem Partido, ambos contendo justificativas e pressupostos "constitucionais". Um deles, Escola sem Partido (2020b), em nossa percepção mais informal, também apresenta artigos e vídeos com frequentes atualizações acerca da temática, além de um link ${ }^{6}$ direcionando os usuários e usuárias (como um cartão de visitas) à página do anteprojeto que se autodenomina "contra a doutrinação nas escolas".

0 argumento para legitimar os objetivos do MESP é o de que seus pressupostos se encontram presentes na Constituição Federal de 1988 (incluindo os artigos 5o e 206ํㅜ) e na Convenção Americana sobre os Direitos Humanos $(\mathrm{CADH})^{7}$ (COMISSÃO INTERAME-

6 Observamos na tela inicial o botão "CONHEÇA A PROPOSTA DO MOVIMENTO ESCOLASEM PARTIDO" que, ao clicarmos, nos direciona a página do anteprojeto - mais didático e sistematizado, em nossa opinião - o que poderia representar esforços de seus idealizadores e idealizadoras em alcançar maior número de apoiadores e apoiadoras.

7 A Convenção Americana sobre Direitos Humanos (CADH), assinada em 1969, é um documento conservador que indica, entre outras proposições, a prevalência da família sobre a educação religiosa e moral dos filhos e filhas. 
RICANA DE DIREITOS HUMANOS, 2020). No entanto, o Movimento ignora o contexto desses documentos e se apropria de seus elementos a favor de interesses e intenções que tampouco convergem com ideias plurais e democráticas.

Miguel (2016) discorre que a importância do MESP no debate público ocorreu devido à incorporação do combate à chamada "ideologia de gênero" - outra vertente da agenda conservadora brasileira. Inicialmente, a ideia de uma "Escola sem Partido" concentrava-se somente no temor da "doutrinação marxista", presente desde o período da ditadura militar. No entanto, com o crescimento das iniciativas de combate à homofobia nas escolas, o Movimento adotou, por meio de grupos religiosos e conservadores, o discurso como um de seus principais focos. "Ao fundi-lo à sua pauta original, o MESP transferiu a discussão para um terreno aparentemente 'moral' (em contraposição a 'político') e passou a enquadrá-la nos termos de uma disputa" (MIGUEL, 2016, p. 596).

Ao canalizar as frustrações cotidianas e a sensação de desencantamento do mundo - alimentada e reforçada pela banalização da informação veiculada pelos meios de comunicação em massa -, o Movimento conseguiu (e ainda consegue) de seus apoiadores e apoiadoras tendências agressivas e intolerantes com aqueles e aquelas que possuem concepções diferentes (CARNIO; NEVES, 2019). Em nossa percepção, a medida liminar proferida pelo atual Governador de São Paulo (mencionada na introdução deste trabalho) pode ser considerada como uma forte extensão das ações conservadoras cultivadas na gênese deste Projeto.

De maneira geral, os vários projetos de lei que fazem parte do MESP se justificam baseados na neutralidade do Estado, criminalizando discussões com doutrinações ideológicas e partidárias sem oferecer uma definição sobre o que vem a ser essa doutrinação (NICOLAZZI, 2016).

Apesar da suposta preocupação com a contaminação político-ideológica das instituições escolares, o Movimento procede, contraditoria- mente, impondo uma única ideologia e retirando dos professores, professoras e estudantes a liberdade de aprender e ensinar que lhes são assegurados como direitos invioláveis.

Fundamentado na compreensão de que conhecer é um ato social, as práticas educativas podem (e devem) ser apartidárias, mas jamais serão neutras, uma vez que a própria escolha do projeto educacional já consiste em uma opção política, que exige o livre diálogo e atuação em sala de aula (NICOLAZZI, 2016).

Salles (2017) afirma que o Movimento possibilitou a criação de uma linha divisória entre as questões que devem ser abordadas no âmbito familiar e as desenvolvidas pelas instituições de ensino. Em um primeiro momento, essa fronteira se referia a temas de ordem moral - mais amplos e indefinidos, tendo como foco principal a questão da "doutrinação ideológica" -, mas essa preocupação de ordem moral tornou-se mais específica, envolvendo as discussões de identidade de gênero e orientação sexual.

Assim, um elemento de um projeto político-pedagógico que visava tratar e prevenir os tipos de violência e opressão que grupos minoritários como mulheres e LGBTs sofrem, na concepção do MESP, se torna 'ideológico' por violar o limite entre escola e família e mais um elemento da 'doutrinação' cometida por professores. (SALLES, 2017, p. 69, grifo do autor).

O slogan "meus filhos, minhas regras" passou a ser usado nas redes sociais e intervenções públicas do grupo como uma forma para sintetizar os ideais do MESP. 0 lema, que subverte seu sentido original de afirmação da autonomia e dos direitos individuais na histórica bandeira feminista "meu corpo, minhas regras", possibilita o recrudescimento de duas negações, quais sejam: a função formativa (plural e democrática) da escola como espaço de convívio com valores diversos e diversamente interpretados daqueles que estão presentes no convívio familiar; e o estatuto da criança como sujeito de direitos, incluindo o direito de conhecer o mundo e de adquirir instrumentos 
para pensar com autonomia (MIGUEL, 2016).

Baseado no Artigo $12^{\circ}$ da Convenção Americana sobre Direitos Humanos, ${ }^{8}$ começou-se uma campanha incentivando notificações extrajudiciais direcionadas às escolas que não respeitassem a soberania moral da família sobre a formação dos estudantes (MIGUEL, 2016). Como forma de alerta aos pais ou responsáveis, o procurador Guilherme Schelb veiculou um vídeo ${ }^{9}$ sobre a "ideologia de gênero", apresentando, inclusive, um modelo de notificação (YOUTUBE, 2020). Entre inverdades e absurdos, Schelb discorre sobre a possibilidade de obter vultosas indenizações devido à "desobediência" das instituições de ensino.

Aderindo à campanha, o MESP também passou a disponibilizar em seu website a notificação extrajudicial ${ }^{10}$ - compreendida, por eles próprios, como um serviço de utilidade pública. Merece destaque o item 20 da proposta, o qual discorre:

[...] meu filho tem ciência da presente notificação e está orientado a reportar-me de forma detalhada as possíveis transgressões à sua liberdade de consciência e de crença e ao meu direito a que ele receba a educação religiosa e moral que esteja de acordo com minhas convicções. (ESCOLA SEM PARTIDO, 2020c).

No entanto, um asterisco no cabeçalho do arquivo direcionado aos pais informa a possibilidade de esconderem a notificação dos filhos e filhas como forma de evitar estresses desnecessários. Em nossa percepção, essa atitude demonstra uma ação baseada na mentira e submissão absoluta das crianças e dos jovens - compreendidas como propriedades. Qual a possibilidade da autonomia se materializar em

80 artigo $12^{\circ}$ da CADH afirma: "Os pais, e quando for o caso os tutores, têm direito a que seus filhos ou pupilos recebam a educação religiosa e moral que esteja acorde com suas próprias convicções" (COMISSÃO INTERAMERICANA DE DIREITOS HUMANOS, 2020).

9 No momento da escrita do artigo o modelo de notificação não estava mais acessível.

10 São apresentados três modelos (em arquivo Word) contendo um mesmo texto, mas com algumas diferenças de acordo com sua especificidade, a saber: uma notificação individual endereçada ao professor e outras duas (individual e coletiva) remetidas à direção da escola. práticas alienantes que camuflam a verdadeira realidade e retiram nossa liberdade de escolha?

A defesa de uma concepção plural de família não pode colocar em segundo plano a ideia de que é necessário proteger, sempre, os direitos individuais dos seus integrantes. E entre estes direitos está o de ter acesso a uma pluralidade de visões de mundo, a fim de ampliar a possibilidade de produção autônoma de suas próprias ideias. (MIGUEL, 2016, p. 605).

Cumpre ressaltarmos que as famílias podem configurar um ambiente hostil e violento, principalmente quando observamos os altos índices de abuso sexual. Dados divulgados em 2018 pelo Ministério da Saúde mostraram que $69,2 \%$ da violência sexual contra crianças ocorreram em suas próprias casas, sendo que $74,2 \%$ eram do sexo feminino. Entre os adolescentes, $58,2 \%$ das incidências foram em seus lares e, destes, 92,4\% representavam o sexo feminino (MINISTÉRIO DA SAÚDE, 2018).

Isso corrobora para refletirmos o importante papel social da escola ao lado das demais instituições responsáveis por essas questões. As discussões sobre gênero - amplamente combatidas pelo Movimento - podem ser um caminho propício para que crianças e adolescentes (principalmente as meninas - as maiores afetadas) identifiquem os abusos e tenham espaço para exporem a situação sem preconceitos e estigmas culturais. Quando oportunizamos uma educação que empodere os sujeitos, as contradições e as barbáries podem ser desveladas, transformando realidades violentas e opressoras, pois se "a educação sozinha não transforma a sociedade, sem ela tampouco a sociedade muda" (FREIRE, 2016, p. 77).

Para Nicolazzi (2016), o MESP subestima a inteligência das pessoas e provoca o medo e a criminalização das práticas educacionais a partir de um falso alarmismo. Esconde por trás do enganoso termo "sem partido" seu real objetivo: extirpar a pluralidade do pensamento. Além dessa enganação, o Movimento também se mostra perverso, uma vez que perverte os marcos legais da Constituição Federal de 1988 
e da Convenção Americana sobre Direitos Humanos (CADH), utilizando-os para fundamentar e divulgar algumas de suas práticas. 0 artigo 5o da Convenção garante a "liberdade de consciência e de crença" e assegura que a expressão da atividade intelectual, artística, científica e de comunicação são livres (COMISSÃO INTERAMERICANA DE DIREITOS HUMANOS, 2020). Por que esses artigos também não são expostos nos sites e nos projetos de lei?

No momento em que representantes da sociedade postulam com orgulho um modelo tradicional de família e bons costumes - que não expressa e tampouco constitui a realidade brasileira -, a escola deve problematizar e se apresentar como resistência democrática, oportunizando transformações equitativas e, sobretudo, voz àqueles e àquelas que não possuem lugar de fala. A escola é o espaço privilegiado para a educação pública, de qualidade e fundamentada na liberdade de ensino, aprendizagem, de pesquisa e divulgação do pensamento, como definido pela Constituição (BRASIL, 1988). "Qualquer projeto contrário a isso não diz respeito à educação, apenas revela interesses privados, eles próprios ideológicos e partidários. Resta, então, saber qual o partido da escola sem partido" (NICOLAZZI, 2016, p. 85).

O MESP corresponde, em sua intenção e proposta, à alienação dos sujeitos e à preservação dos mitos. 0 mito de que todos e todas são iguais e possuem os mesmos direitos não importando sua cor, crença, gênero, concepção. 0 mito da igualdade de oportunidades quando a violência e a impossibilidade são os únicos projetos que as maiorias submissas conseguem vislumbrar. Precisamos, por consequência, de uma escola plural, integrada e com partidos, que mostre as incoerências convenientemente silenciadas e que não favoreça o partido da opressão e injustiça.

\section{Mais algumas provocações}

Vivenciamos a atual sociedade técnicocientífica, suas controvérsias e incertezas nos perguntando, assim como se questionou Kant (1974), se estamos em uma época esclarecida, ou permanecemos no medo e na menoridade. Foucault (2000) afirma que muitos acontecimentos históricos nos convenceram de que a Aufklärung não nos tornou maiores; a modernidade não teria conseguido alcançar esse objetivo. 0 projeto que pretendia elevar os sujeitos à condição de senhores da natureza e da verdade científica proporcionou a falta de questionamentos e criticidade, impedindo o entendimento humano de conhecer as coisas tais como elas são e transformando os homens e mulheres em instrumentos de dominação, poder e exploração (ADORNO; HORKHEIMER, 2006).

Freire (2019) afirma que onde há a dominação das consciências a educação se materializa como intrínseca às concepções hegemônicas. Em razão disso, não poderá prevalecer uma educação capaz de desvelar as contradições existentes pela "ordem" social, pois existirão apenas situações que oportunizem a preservação dos mitos; uma pseudodemocratização dos saberes que exclui e violenta as maiorias submissas ao mesmo tempo em que as transforma em resignadas e pacientes. "A ação conformista é uma prática rotineira, reprodutiva e repetitiva que reduz o realismo aquilo que existe e apenas porque existe" (SANTOS, 2007, p. 32).

Ao retirar de professores, professoras e estudantes a autonomia sobre os processos de ensino e aprendizagem, o MESP os impede de atuar como sujeitos e descarta o potencial socializador da escola (SALLES, 2017), conferindo aos docentes a função de depositar conteúdos vazios, sem significados e que representam retalhos da realidade.

Não há como observarmos as transformações necessárias nessa educação bancária, uma vez que os saberes não são aqueles de experiência feita, mas sim de experiência narrada, sugerindo a passividade e uma consciência aberta aos depósitos que o mundo faz (FREIRE, 2019).

Foucault (2000) apreende os sujeitos como agentes e elementos da Aufklärung - uma vez que ela se materializa à medida que os homens 
e mulheres exercem a coragem e a ousadia para saber. Todavia, ser esclarecido mostra-se incoerente diante da inércia e apatia das práticas educativas que mantêm o pensamento preso à imediaticidade, com conteúdos prontos e padronizados.

Kant (1974) credita, de certo modo, aos sujeitos a culpa por suas menoridades. No entanto, como desenvolver a maioridade em espaços que não proporcionam esse desenvolvimento? Como ter a coragem e a ousadia para transcender as tutelas sociais quando os progressos em relação à consciência da liberdade são, eles próprios, estimulantes à permanência da falsa liberdade?

De acordo com Miguel (2016), o frequente argumento usado por Nagib para legitimar o Movimento consiste na ideia de que a liberdade de expressão não pode ser realizável nas salas de aula, ficando implícito a utópica ideia de professores e professoras como meros transmissores de informações e conteúdos desconexos daquilo que os configuram sócio-historicamente.

Nesse entendimento, "se há liberdade de expressão, não há qualquer possibilidade de cobrar respeito a qualquer parâmetro curricular" (MIGUEL, 2016, p. 614), significando subjugar irresponsabilidade a numerosas profissões. Ao usar sua liberdade de expressão no jornalismo, por exemplo, o profissional não abole seu compromisso ético de relatar a realidade de maneira apurada; ou no caso de cientistas, que desfrutam de suas liberdades de expressão sem eximir as diretivas de suas atividades (MIGUEL, 2016).

A percepção kantiana sobre os usos público e privado da razão nos auxilia a contemplar os aspectos envolvidos nesse discurso, pois embora a liberdade dos sujeitos se constitua de maneira individual, suas ações se desenvolvem segundo fins construídos sócio-historicamente. Trata-se de agir e refletir criticamente a fim de que a razão privada (particular) exija, também, um julgamento ético e moral que impossibilite sua livre utilização.
No caso do professor, a liberdade de expressão toma a forma da liberdade de cátedra, que significa a liberdade para escolher o caminho que julga melhor para promover a formação de seus alunos. A liberdade de expressão do professor não é uma forma de irresponsabilidade; ao contrário, é uma necessidade de sua responsabilidade profissional. (MIGUEL, 2016, p. 614).

Sobre isso, Foucault (2000, p. 339) considera que para Kant "a razão deve ser livre em seu uso público e que deve ser submissa em seu uso privado". Isto significa que a razão privada exige um julgamento da própria razão e impede seu uso de maneira livre, pois a Aufklärung não consiste apenas na busca individual de uma razão livre, mas na sobreposição de seu uso universal, de seu uso livre e de seu uso público.

Ao fundamentar o uso universal da razão (fora de qualquer fim particular) no próprio sujeito, Foucault (2000) compreende a Aufklärung como um problema político, já que essa liberdade individual poderia representar uma negação das regras e leis pré-estabelecidas, complementando: "coloca-se a questão de saber como o uso da razão pode tomar a forma pública que lhe é necessária, como a audácia de saber pode se exercer plenamente, enquanto os indivíduos obedecerão tão exatamente quanto possível" (FOUCAULT, 2000, p. 340).

A pretensa abordagem dos conteúdos somente de forma descritiva não é neutra, pois corrobora para a interiorização de preconceitos e barbáries contra as maiorias ignoradas. 0 discurso sobre gênero - um dos símbolos do Movimento - oportuniza, ainda mais, estereótipos culturalmente sedimentados, como as barreiras que dificultam o empoderamento de meninas e mulheres. Para Santos (2007, p. 27), "não há conhecimento que não seja conhecido por alguém para alguns objetivos. Todos os conhecimentos sustentam práticas e constituem sujeitos", diferentemente do que é proposto (ideologicamente) pelo MESP. Uma concepção universal, única e que despreza todas as diferenças e singularidades.

Aceitando uma Escola sem Partido estaríamos corroborando para que a irracionalidade 
se constitua como parte de um dos elementos fundamentais da sociedade: a educação, que

[...] não podendo jamais ser neutra, tanto pode estar a serviço da decisão, da transformação do mundo, da inserção crítica nele, quanto a serviço da imobilização, da permanência possível das estruturas injustas, da acomodação dos seres humanos à realidade tida como intocável. (FREIRE, 2016, p. 66).

Trata-se de um pretexto para criminalizar o pensamento crítico, a reflexão, a autonomia, a liberdade e uma formação que respeite as diferenças e oportunize que todos e todas sejam conscientes de seu papel, individual e coletivo, na reprodução e transformação das realidades (MIGUEL, 2016). "De fato, a democracia não precisa de uma escola 'neutra', mas de uma escola que promova os valores básicos que permitem a própria existência de uma ordem democrática" (MIGUEL, 2016, p. 616, grifo do autor). Tais valores incluem, em nossa percepção, a igualdade, o pluralismo e a solidariedade dos existires.

O Movimento Escola sem Partido é, por isso, homogeneizante e totalitário. Seu objetivo não é a liberdade e autonomia dos sujeitos, mas mantê-los em sua menoridade e no mundo de engodos que, alienando-os, os acondicione passivos, submissos e prisioneiros dos mitos. A liberdade de aprender é inseparável da liberdade de ensinar, da pluralidade de ser e se constituir como cidadãos e cidadãs. Defendemos uma escola democrática, que integre, perceba e respeite as diferenças e os partidos, quaisquer que sejam eles.

\section{Considerações finais}

Theodor Adorno iniciou seu célebre texto, Educação após Auschwitz (ADORNO, 1995), compreendendo como tarefa inegável da escola a luta para que a barbárie e a injustiça não se materializem. "A exigência que Auschwitz não se repita é a primeira de todas para a educação. De tal modo que ela procede quaisquer outras que creio não ser possível nem necessário justificá-la" (ADORNO, 1995, p. 119).

Considerando as interfaces realizadas durante o texto, recorremos ao objetivo proposto, que é: refletir, à luz da Aufklärung, as possibilidades de uma práxis educacional apartidária quando almejamos uma educação em defesa da liberdade, autonomia e justiça social.

Ao impedir uma abordagem plural, o MESP retira das instituições escolares a possibilidade de contribuir na construção de uma sociedade mais justa e solidária, que respeite as diferenças e perceba todos e todas como cidadãos e cidadãs. Ele impossibilita que tenhamos acesso aos conteúdos e informações historicamente situados e necessários para apreendermos a complexidade do mundo e transformarmos as realidades. Uma escola partida em sua essência ontológica: a Aufklärung, e que toma o partido da violência e opressão.

A ideia abrangente, totalitária e unificadora - promovida pelo Movimento - desenvolverá, ainda mais, a invisibilidade e inexistência das maiorias submissas. A igualdade de direitos não se concretizará fundamentada na universalidade; ao contrário, somente a partir da liberdade de ensinar, aprender, se realizar e se constituir como sujeitos esclarecidos, que ousem saber.

Queremos, sim, uma escola sem partido. Contudo, não no sentido defendido pelo MESP e seus apoiadores e apoiadoras. Desejamos que a escola não tenha práticas baseadas em um projeto ideológico e mistificador, que esconde a alienação atrás da amistosa campanha a favor da família, da moral e dos bons costumes. Lamentavelmente, a classe social, a religião, a cor e o gênero dessa família sejam predeterminados pela cultura hegemônica.

Uma escola sem partido para que Auschwitz não se repita seria nossa principal defesa, de forma que "justificá-la teria algo de monstruoso em vista de toda monstruosidade ocorrida" (ADORNO, 1995, p. 119). Uma escola que empodere os sujeitos na transformação das injustiças, desvelando os mitos e compreen- 
dendo a realidade histórica como projeto e possibilidade, sempre plural.

\section{REFERÊNCIAS}

ADORNO, Theodor. Educação após Auschwitz. In: ADORNO, Theodor (org.). Educação e emancipação. São Paulo: Paz e Terra, 1995. p. 119-138.

ADORNO, Theodor; HORKHEIMER, Max. Dialética do esclarecimento: fragmentos filosóficos. Rio de Janeiro: Zahar, 2006.

BRASIL. Presidência da República. Casa Civil. Constituição da República Federativa do Brasil de 1988, de 5 de outubro de 1988. Brasília, DF, 2016. Disponível em: http://www.planalto.gov.br/ ccivil_03/constituicao/constituicao.htm. Acesso em: 01 fev. 2020.

CARNIO, Michel Pisa; NEVES, Marcos Cesar Danhoni. O projeto escola "sem" partido como uma falsa projeção do campo educacional. Devir Educação, Lavras, MG, v. 3, n. 1, 2019. Disponível em: http://devireducacao.ded.ufla.br/index.php/ DEVIR/article/view/131/87. Acesso em: $01 \mathrm{fev}$. 2020.

CHAUÍ, Marilena. Convite à filosofia. 6. ed. São Paulo: Ática, 1995.

COMISSÃO INTERAMERICANA DE DIREITOS HUMANOS. Convenção Americana sobre Direitos Humanos. Disponível em: https://www.cidh.oas. org/basicos/portugues/c.convencao_americana. htm. Acesso em: 30 jan. 2020.

ESCOLA SEM PARTIDO. Sobre nós. 2020a. Disponível em: http://www.escolasempartido.org/ quem-somos/. Acesso em: 30 jan. 2020.

ESCOLA SEM PARTIDO. Por uma lei contra o abuso da liberdade de ensinar. 2020b. Disponível em: https://www.programaescolasempartido.org/. Acesso em 30 jan. 2020.

ESCOLA SEM PARTIDO. Notificação extrajudicial - arma das famílias contra a doutrinação nas escolas. 2020c. Disponível em: http:// www.escolasempartido.org/artigos-e-videos/ notificacao-extrajudicial-arma-das-familiascontra-a-doutrinacao-nas-escolas/. Acesso em 30 jan. 2020.

FOUCAULT, Michel. O que são as luzes? In: FOUCAULT, Michel (org.). Ditos e escritos II. Rio de Janeiro: Forense Universitária, 2000. p. 335-351.
FREIRE, Paulo. Pedagogia da indignação: cartas pedagógicas e outros escritos. 3. ed. Rio de Janeiro: Paz e Terra, 2016.

FREIRE, Paulo. Pedagogia do oprimido. 67. ed. São Paulo: Paz e Terra, 2019.

JUÍZA manda Dória devolver apostilas recolhidas por "apologia a ideologia de gênero". O Estado de S. Paulo, São Paulo, 10 set. 2019. Disponível em: https://educacao.estadao.com. $\mathrm{br} /$ noticias/geral,juiza-manda-doria-devolverapostilas-recolhidas-por-apologia-a-ideologia-degenero,70003005063. Acesso em: 20 jan. 2020.

KAHLMEYER-MERTENS, Roberto. Dos usos público e privado da razão segundo Immanuel Kant. Passages de Paris, Paris, v. 7, p. 223-231, 2012. Disponível em: http://www.apebfr.org/ passagesdeparis/editione2012/articles/pdf/ PP7_varia7.pdf. Acesso em: 30 jan. 2020.

KANT, Immanuel. Resposta à pergunta: que é "esclarecimento" (Aufklärung)? In: KANT, Immanuel (org.). Immanuel Kant - textos seletos. 2. ed. Petrópolis, RJ: Vozes, 1974. p. 100-117.

MIGUEL, Luis Felipe. Da "doutrinação marxista" à "ideologia de gênero" - Escola Sem Partido e as leis da mordaça no parlamento brasileiro. Direito \& Práxis, Rio de Janeiro, v. 7, n. 15, p. 590-621, 2016. Disponível em: https://www. epublicacoes.uerj.br/index.php/revistaceaju/ article/view/25163/18213. Acesso em: 20 jan. 2020.

MINISTÉRIO DA SAÚDE. Análise epidemiológica da violência sexual contra crianças e adolescentes no Brasil, 2011 a 2017. Boletim Epidemiológico, Brasília, DF, v. 49, n. 27, p. 1-17, 2018. Disponível em: https://portalarquivos2.saude.gov.br/images/ pdf/2018/junho/25/2018-024.pdf. Acesso em: 31 jan. 2020.

NICOLAZZI, Fernando. Qual o partido da escola sem partido? Revista do Lhiste, Porto Alegre, v. 3, n. 5, p. 82-85, jul./dez. 2016. Disponível em: https://seer.ufrgs.br/revistadolhiste/article/ view/79154/45987. Acesso em: 20 jan. 2020.

SALLES, Diogo. Concepção pedagógica e o projeto educacional conservador e reacionário do movimento escola sem partido: uma crítica a partir da função de subjetivação do processo de ensino-aprendizado. RevistAleph, Niterói, RJ, n. 28, p. 64-87, 2017. Disponível em: http://periodicos. uff.br/revistaleph/article/view/39186/22623. Acesso em: 20 jan. 2020. 
SANTOS, Boaventura de Sousa. Para além do pensamento abissal: das linhas globais a uma ecologia de saberes. Revista Crítica de Ciências Sociais, Coimbra, Portugal, v. 78, p. 3-46, maio/ ago. 2007.

YOUTUBE. Ideologia de gênero. Disponível em: https://www.youtube.com/watch?v=9yjeAFXJgQA. Acesso em: 30 jan. 2020.

WURMEISTER, Fabiula. 0 educador usurpa uma função que é da família. Gazeta do Povo, Foz do Iguaçu, 7 ago. 2012. Disponível em: https:// www.gazetadopovo.com.br/vida-e-cidadania/oeducador-usurpa-uma-funcao-que-e-da-familia293fk255btxfvp15ip2ikn4ni/. Acesso em: 21 jan. 2020.

Recebido em: 16/02/2020

Aprovado em: 27/05/2020 